\title{
Contemporary Issues in Lubricant Industry in Sri Lanka, Proposing guideline for policy direction.
}

\section{by}

Kotuwegoda Palliyaguruge Rohitha Prasad Shirantha. (Registration Number 5266FM11106)

A research submitted to the University of Sri Jayewardenepura in partial fulfillmentt of the requirementss fiom the Degree of Masther of Bussiness Adhministration in Whangement program 2014. 
Contemporary Issues in Lubricant Industry in Sri Lanka, Proposing guideline for policy direction.

\begin{abstract}
by
Kotuwegoda Palliyaguruge Rohitha Prasad Shirantha.

(Registration Number 5266FM11106)
\end{abstract}




\section{Declaration.}

The work described in this research was carried out by me under the supervision of Prof.

(Mrs.) R.L.S. Fernando and a report on this has not been submitted in whole or in part to any university or any other institution for another Degree/ Diploma".

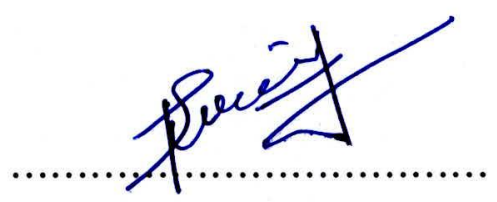

K. P. G. R. P. Shirantha
$10105 / 15$

Date. 


\section{Declaration by the Supervisors.}

"We certify that the above statement made by the candidate is true and that this thesis/research/project is suitable for submission to the University for the purpose of evaluation".

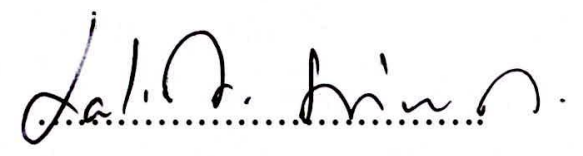

Prof. (Mrs) R.L.S. Fernando.

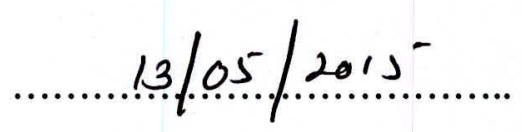

Date 


\section{Table of Contents}

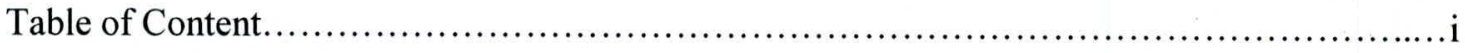

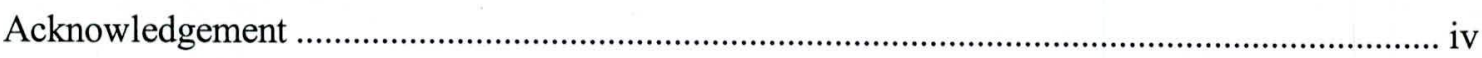

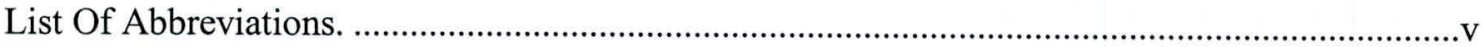

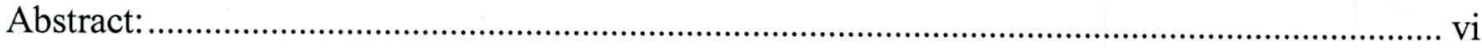

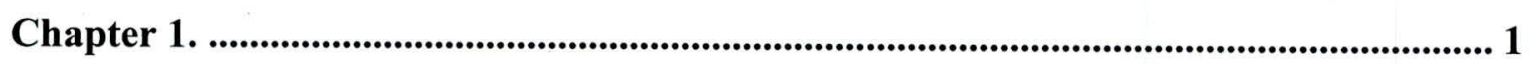

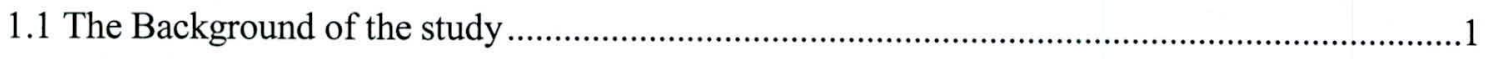

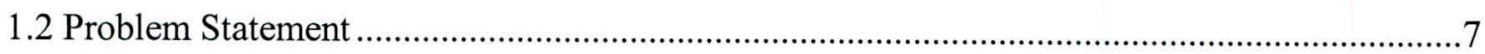

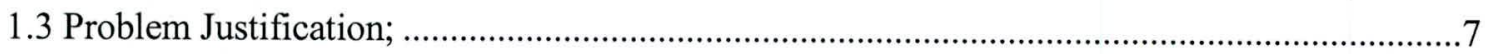

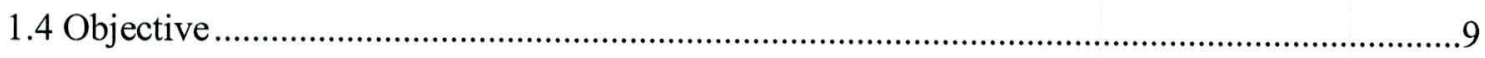

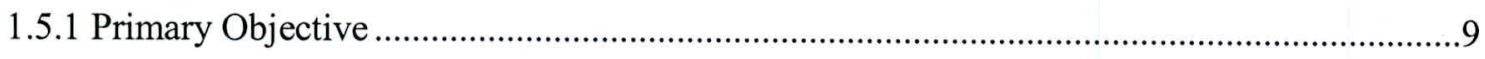

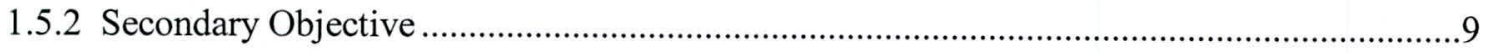

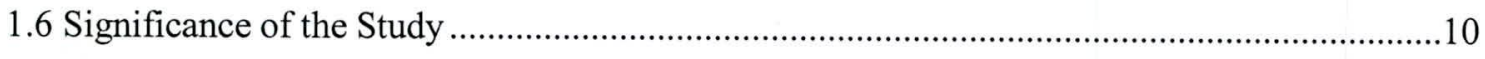

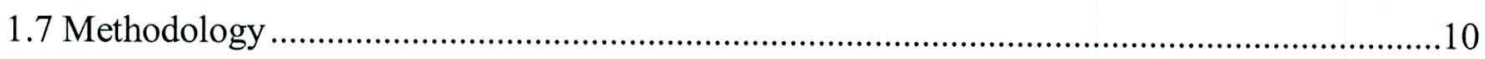

1.7.1 Sample

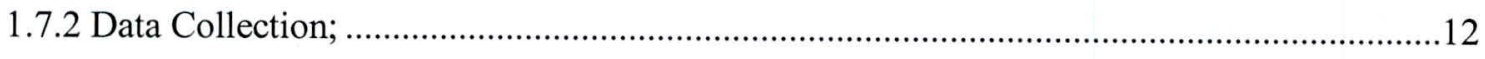

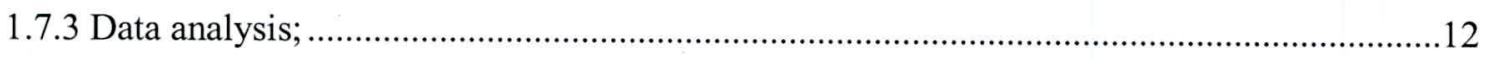

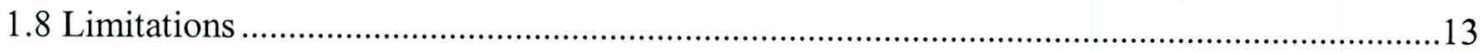

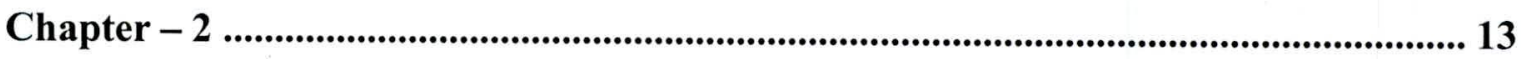

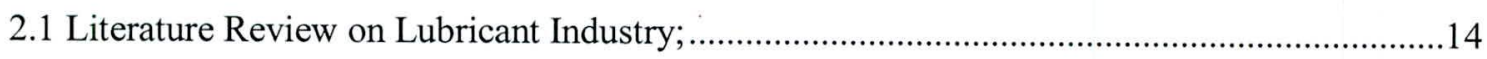

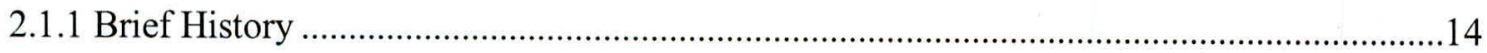

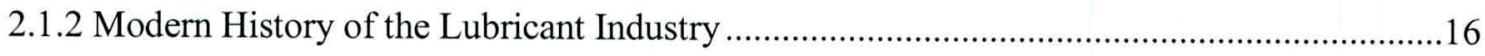

2.1.3 Recommended Standards for Lubricant Products; .............................................................. 18 


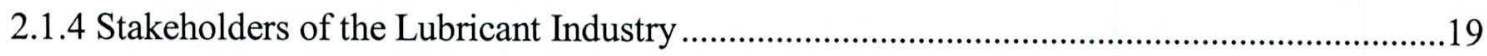

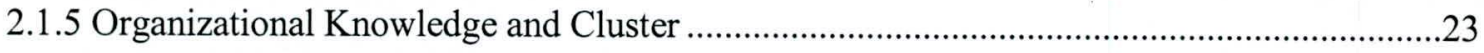

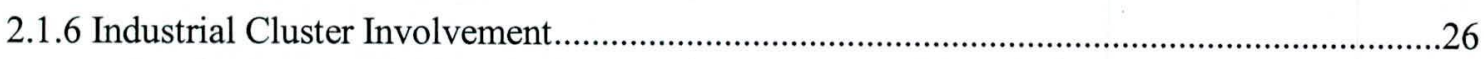

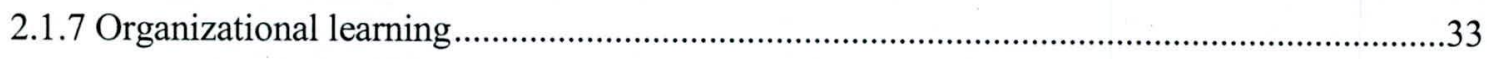

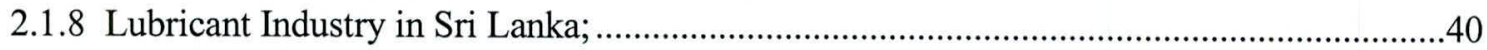

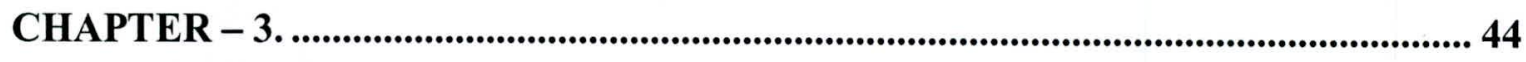

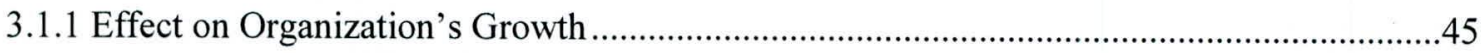

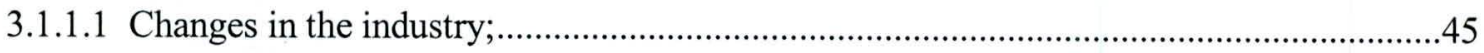

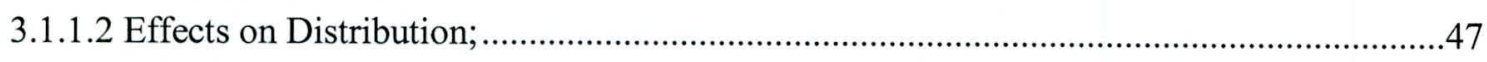

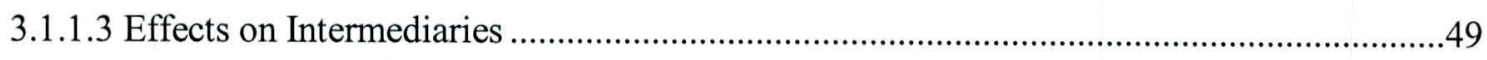

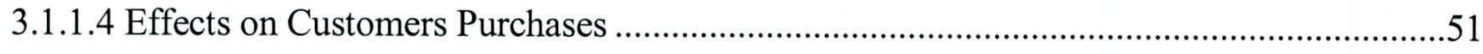

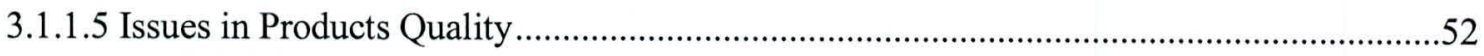

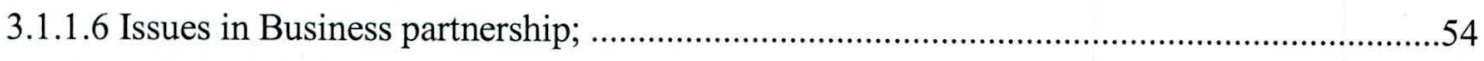

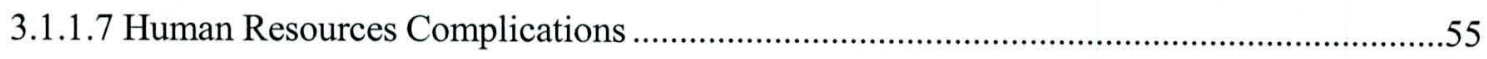

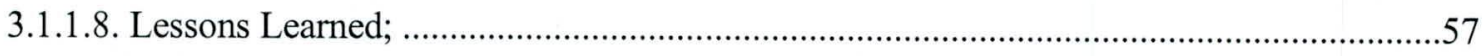

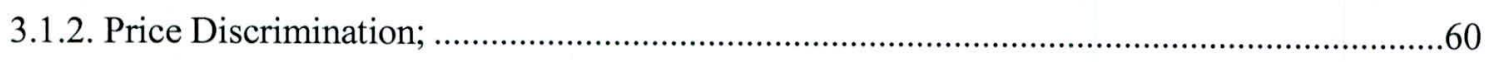

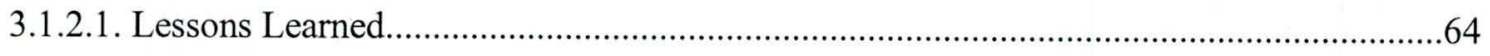

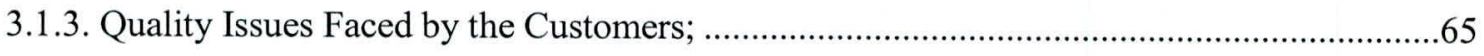

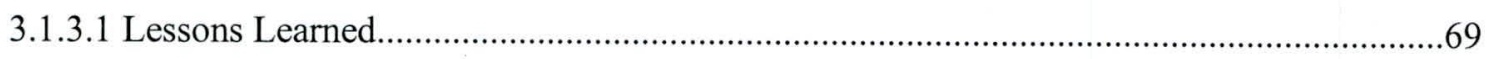

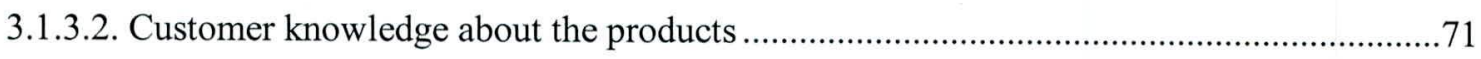

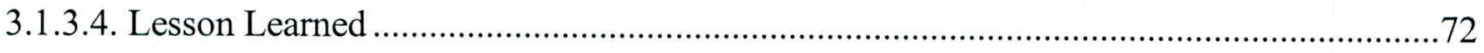

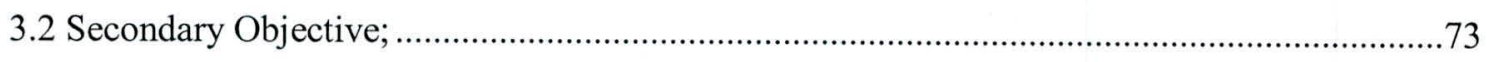

3.2.1. Criteria 01. Product Registration based on goodwill and the API recommendation. ...........75

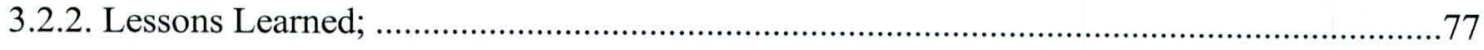

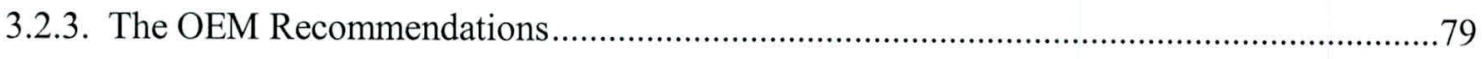




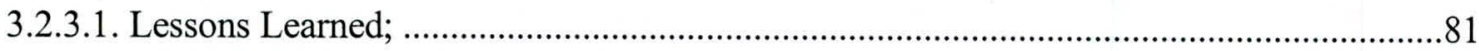

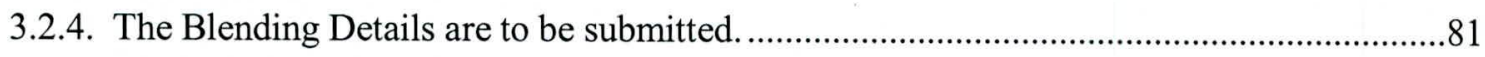

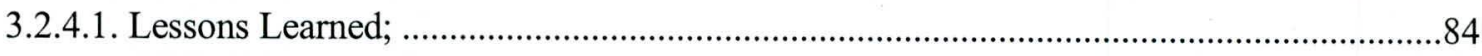

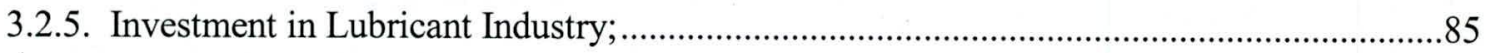

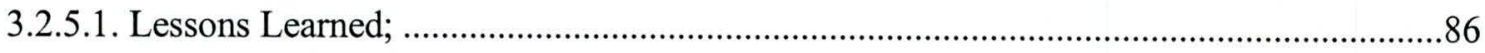

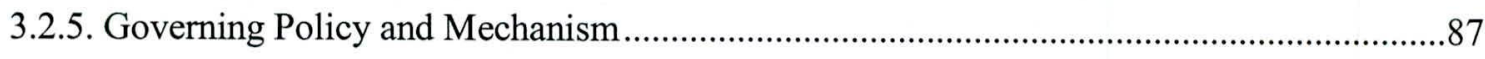

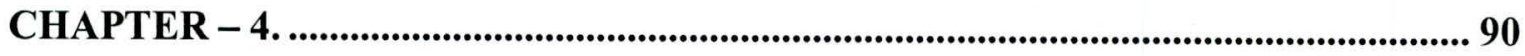

4.1.1. Amplification of Theoretical Framework …...................................................................

4.1.2. Non availability of Quality Checking Mechanism............................................................... 91

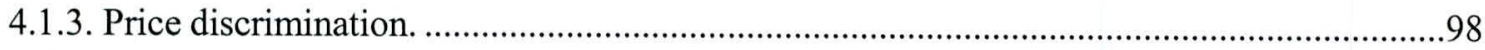

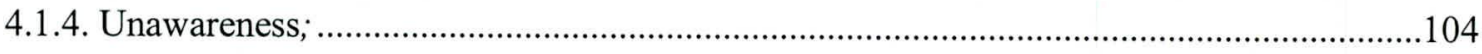

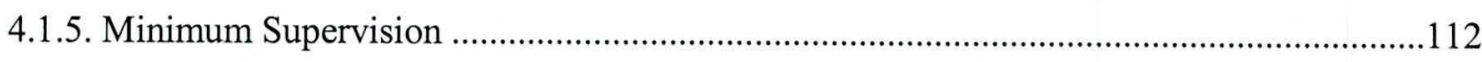

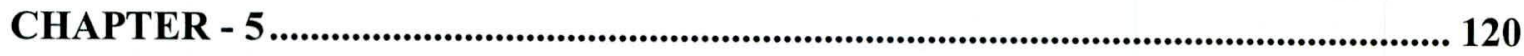

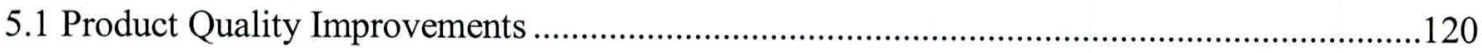

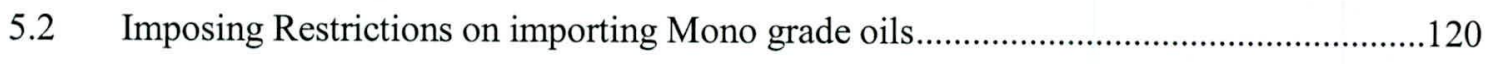

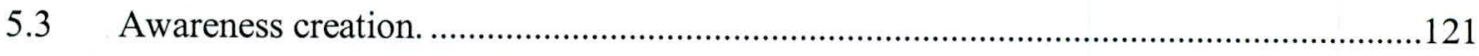

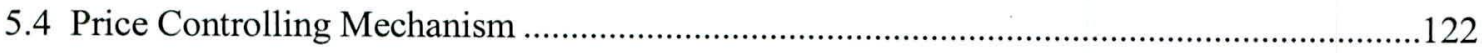

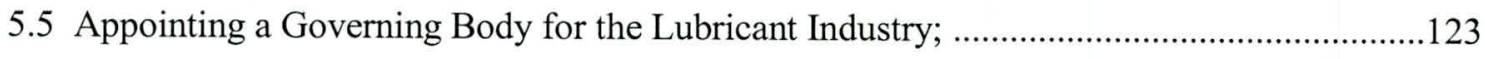

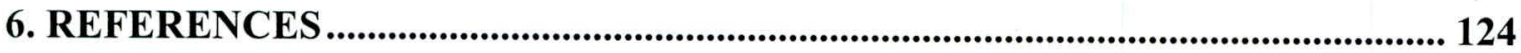

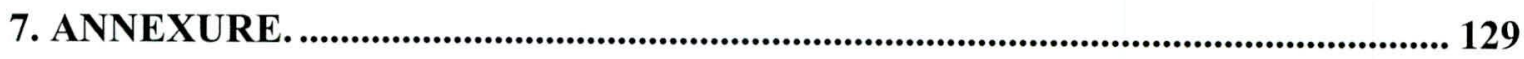

7.1. Sri Lanka Standard 1374 : 2009 UDC 665. 765 ..................................................................xx

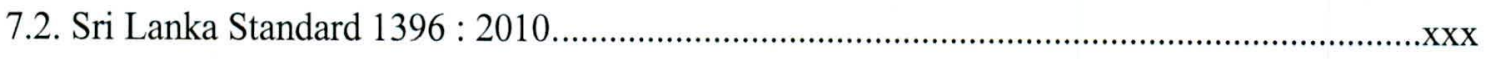

7.3. Sri Lanka Standard 1409 : 2011 UDC 665.765: 629. 326 ..................................................xxx 


\section{ACKNOWLEDGMENT}

At the very outset, I would like to express my sincere gratitude to the academia of the faculty of Management Studies and Commerce of the University of Sri Jayewardenepura and former coordinator of Management Studies Dr. P.D. Nimal and the coordinator Dr. P.J. Kumarasinhe for their invaluable cooperation and value addition to the most prestigious MBA program in Sri Lanka.

I feel a deep sense of gratitude to my supervisors Prof. (Mrs) R.L.S. Fernando for her fullest support, invaluable time, encouragement and academic guidance given whole heartedly to make this study a successful contribution to the nation.

Finally, I would like to state my sincere thanks to the respondent who helped me in collecting the primary data for my study and all the members of my Family, members of 2011 MBA batch and the non-academic staff who helped me in numerous ways in making this study a success.

Contemporary Issues in Lubricant Industry in Sri Lanka, Proposing Guideline for Policy Direction.

Kotuwegoda Palliyaguruge Rohitha Prasad Shirantha 


\section{List of abbreviations.}

\begin{tabular}{|c|c|}
\hline$i$. & LPG \\
\hline ii. & OEM \\
\hline iii. & API \\
\hline$i v$. & $\mathrm{AD}$ \\
\hline$v$. & ACEA \\
\hline & Auto. \\
\hline$v i$. & JASO \\
\hline vii. & SAE \\
\hline viii. & SLSI \\
\hline$i x$. & PLC \\
\hline$x$ & $\mathrm{KL}$ \\
\hline$x i$. & PUCSL \\
\hline xii. & LIOC \\
\hline xiii. & LKR \\
\hline xiv. & BTL \\
\hline$x v$. & PRDC \\
\hline & Committee \\
\hline$x v i$. & LLL \\
\hline xvii. & СТTC \\
\hline xviii. & AMW \\
\hline$x i x$. & CAA \\
\hline$x x$. & IOC \\
\hline xxi. & DS \\
\hline xxii. & QCM \\
\hline
\end{tabular}

- $\quad$ Liquefied Petroleum Gas.

- $\quad$ Original Equipment Manufacturers.

- $\quad$ American Petroleum Industry.

- Anno Domini.

- $\quad$ Association des Constructers of European

- Japanese Automobile Society.

- $\quad$ Society of American Engineers.

- $\quad$ Sri Lanka Institute of Standards.

- $\quad$ Public Liable Company

- $\quad$ Kilo Liters.

- $\quad$ Public Utility Commission of Sri Lanka.

- $\quad$ Lanka Indian Oil Company.

- Lankan Rupees.

- Below The Line.

- $\quad$ Petroleum Resources Development

- $\quad$ Lanka Lubricant Limited.

- Caltex Trading and Transport Corporation.

- Company Name

- Consumer Affairs Authority.

- Indian Oil Company.

- $\quad$ Brand Name given for a Caltex product.

- Quality Checking Mechanism. 


\section{ABSTRACT:}

Purpose - The study was done to identify the contemporary issues in the Lubricant Industry in Sri Lanka and to propose a guideline for policy direction to the governing body. The study was done by using both qualitative and quantitative research techniques. The sample population was interviewed by using properly design open ended and close ended questionnaires to identify the prevailing issues in the Lubricant Industry and to understand the perception of the Lubricant users. Total sample was selected in different industries and in different social scales. The information and the data collected was systematically analyzed and identified four key areas to be develop and implemented by the governing body that could propose a guideline for policy framework for the future studies.

The study explored the contemporary issues in the lubricant industry and identified the key issues pertaining to the development of the industry. A clear explanation related to the study is given under the problem statement, and the problem justification and two objectives primary and secondary have been developed to direct the study in the right direction based on the problem statement. As there were only few empirical researches done focusing the lubricant industry it was found difficult to find literature but important information related to the industry such as history of the lubricant industry and the modern history with lucrative information about Sri Lankan lubricant industry has been provided. Under literature review a few topics have been discussed that would help in developing the theoretical framework in a more effective manner such as organizational learning, knowledge and cluster based empirical research done in other industries. 
Under the discussion and analysis key issues pertaining to the industry have been discussed, elaborating contemporary issues along with the research findings and each discussion is concluded with the lesson learned.

In addition to the factors identified in the industry this study is focused on the governing mechanism of the industry. The contemporary governing mechanism and the drawbacks of the governing mechanism are discussed. Theoretical framework is derived from the discussion carried out in the study with proper in developing the policy framework for a better governing mechanism for the industry.

Study is concluded with recommendations to be implemented regarding future policy directions purely based on the study and the discussions carried out with the sample selected. This study was done purely through the interviews done with a carefully selected sample throughout the Island and the key persons in the industry and the governing body.

Key Words - Contemporary, Policy framework, systematically, dimensions, Organizational Learning. 


\section{Chapter 1.}

\subsection{The Background of the study}

This study will be based on the Lubricant industry of Sri Lanka which is a part of the Petroleum industry. Since the industrial revolution started, an industry like petroleum has been playing a major role in any country in the world as it is the foundation for the energy driven societies of the world. This will cover the industry behavior, its organization and governing mechanism. Basically, under Petroleum industry there are three main categories such as Fuels, LPG and Lubricants. A US\$ 15 billion industry (central Bank Report 2014) is shared among the players who are actively engaged in the petroleum business. The industry is governed by the several institutes under the Petroleum Ministry. High trade deficit, high international oil prices and increased domestic administration cost have wider impact on the petroleum industry. The key disadvantage of the industry for its continuous growth is the very minimal knowledge customers have about the product they use and not having the proper implementation of policies to manufacture quality and environmental friendly products within Sri Lanka.

After the liberalization of the Lubricant industry many organizations entered the Sri Lankan lubricant industry which had a higher impact on the existing player's profitability and the behavior of the industry and also had caused never ending competitions among the lubricant organizations in the industry.

Most of the industry experts and leading business consultants in the world stress that healthy competition is the most important tool to develop, regularize and standardize any 
industry in the world. And also, they pointed out that the benefits go to end users. Is this the reality in the Sri Lankan lubricant industry with a high level of competition? The Sri Lankan lubricant industry, before the liberalization was a monopoly market and Chevron Lanka Limited was the only player who was supplying lubricants to the Sri Lankan market. According to industrialists (a well-known businessman in Matara and leading businessmen in main cities) there was no much of scarcity in the market place but there was a demand for the products in the market place. From this anyone can understand the size of the lubricant market and it is understood that year by year industry is growing in some percentage. And one organization will not be able to supply the demand created by the market. The Government or the authorized parties will have to develop a healthy competition among the competitors to pass the benefit to the relevant parties in the market place. Under the petroleum industry, there are three main industries. Except lubricant industry, the other two industries fuel and LPG (liquid Petroleum Gas) are running with very low competition and only the lubricant industry is having a high level of competition.

With this high competition, industrialists (Organizations that are in operation) or the end user getting the benefits from the industry is very rare. According to a well experienced industrialist working for Chevron Lanka Ltd, some intermediaries are getting the benefit because of the high competition that is created among the organizations. Most of the senior position holders in the industry pointed out that a high level of competition would jeopardize the norms of the industry. Authorities are having a vivid picture about the competition and most of them think that the competition will bring the end user benefits. And they are unable to see the deep flame under the ash because of the non-availability of 
the information on the real picture and the poor analysis of the industrialists' issues and the requirement to perform in a healthy environment.

The lubricant industry had been a monopoly market for a longer period for Sri Lankan consumers and with the liberalization, price discrimination can be found in the industry and most of the new comers and the industrialists who are dealing with quality and the standard products are facing numerous issues in maintaining the organizational standards and operations in Sri Lanka.

Price discrimination can be seen in any industry in a minor way and most of the organizations discussed, introduced, argued this as a pricing war between two companies. Some industries need this kind of situation to give the benefit to key organizations that are in the operation of manufacturing. Especially this kind of situation is fine for the market like a duopoly. In the lubricant industry price discrimination causes a heavy damage as the investors are trying to face the price discrimination in different ways which will badly affect to the industry norms and moreover industrialists are complaining about the deviation from the rules and regulations of the industry which will badly affect to the future of the industry and the effective and efficient operation of the future business. The organizations that are dealing with reputed organizations in the world are facing numerous issues in dealing with this kind of price prejudice. Most of the organizations that had entered the market recently with heavy investment are trying to find solutions for recovering their investment and most of the new comers get their hands burnt in this price discrimination without understanding the futuristic issues they are to face in surviving in the industry. 
In other two main industries of the petroleum industry namely LPG and Fuel the prices are governed by the government. Hence, the control over the price is done by the authorities for the basic products and the industrialists are allowed to charge an extra premium for value addition to the products. With this price ceiling control mechanism customers and the industrialist get the benefit and they are allowed to gain certain margins for their investment. For the lubricant industry there are no such rules and regulations to govern the price or the industry.

Although the government had allowed 14 players (PUCSL annual report) to enter the Sri Lankan Lubricant market no policies or standardization is introduced to the Lubricant industry to govern and control the activities and maintain the quality of the industry.

The Lubricant industry despite being one of the key industries in petroleum, the government has not taken any futuristic actions to formulate or standardize the industry actors and forces. Mainly policies for the industry are not introduced so far and there is no proper body with the authority to analyze the industry, regularize, and govern and to take the actions against the industrialists who are deviating from the given instructions.

To govern any industry in a proper manner that can bring good results to the industrialists, customers and the people who are involved in the business it needs to be standardized in a proper manner. Mainly the government needs to introduce a proper mechanism to govern the widely spread industries like lubricants. It should be implemented with a proper understanding of the industry behavior, capabilities and the industrialists involved in the 